\title{
Effective Inventory Management of Entrepreneurs in Eastern Part Thailand: 10 Big Questions
}

\author{
Adisak Suvittawat \\ Burapha University, International College, Thailand \\ adisaku@buu.ac.th
}

\begin{abstract}
The objective of this research is finding the variables which effect on entrepreneurs' inventory management in eastern part of Thailand. The entrepreneurs have been identified in 2 difference sizes, large and small as the inventory management variables must be different. The results show that inventory management of large size were accepted by the entrepreneurs are space utilization, product sample, product feature differentiation, effective inventory management system, inventory management objective, effective inventory picking system, inventory cost reduction, regular problem happen, effective IT system and specific soft ware for inventory management. The results show that inventory management of small size were accepted by the entrepreneurs are specific soft ware for inventory management, effective IT system, inventory management objective, effective inventory picking system, regular problem happen, product feature differentiation, inventory cost reduction, product sample, space utilization and effective inventory management. Inventory management in small firm and big firm has significantly priorities as the big firms have advantage in space utilization but need specific soft ware for inventory management due to big firms have more products or inventories items than small firms.
\end{abstract}

Keywords: Effective, Inventory, Management, Entrepreneurs, Thailand

\section{Introduction}

Currently Thai entrepreneurs of logistics business are facing many challenge problems such as ineffective purchasing planning, high production cost, high transportation cost and ineffective inventory management which decrease Thai entrepreneurs' competitiveness. Since the competition in supply chain management is highly increasing due to many foreign companies are coming and doing logistics businesses then it has directly effect on Thai entrepreneurs businesses. One part of the competitive advantage is reducing the cost through effective inventory management which enhances Thai entrepreneurs' capabilities. Effective inventory management has many dimensions which depend on business types, size of the business or competition environments then the study of Thai entrepreneurs' effective inventory management variables will provide competitiveness advantage for their inventory management in the future. This study focuses on Thai entrepreneurs' effective inventory management parameters which separately study on small size and big size companies. The finding of this study will benefits Thai entrepreneurs more.

\section{Methodology}

This is an exploratory research which focuses on new factors that affected on effective inventory management factors in Thai's logistics business. The research also explores the degree to which each effective inventory management factor had an impact on Thai's logistics competitiveness. The research has been applied quantitative methods by using questionnaires for qualitative contextual tools. A secondary data were taken on literature's review and confirmation of research finding. The research process has been started with a literature review. Based on the literature review, a parameters' measurements of worker related issues were created, which was used to consult with supervisors and experts, before conducting the pilot surveys with the entrepreneurs. The measures were certainly applied to the results of the survey final version. The survey results have been analyzed by using a mean and SD model. The conclusions have been drawn from the study's findings. The exploratory research was focus on 50 entrepreneurs who are doing the logistics business by using the questionnaires. After the data were analyzed then the observations of workers have been done to confirm the results finding. 
Figure 1: Conceptual Framework of this Study

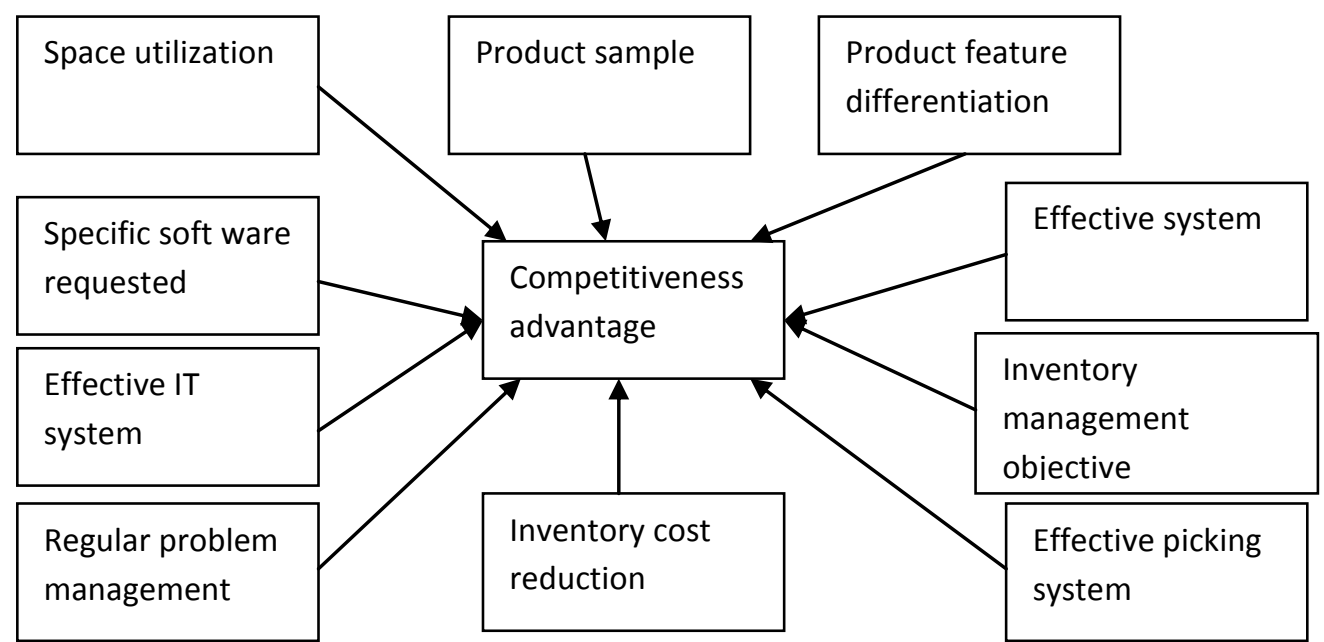

\section{Literature Reviews}

Controlling the inventory storage ratio at the fixed warehouse space capacity and inventory reorder points, the backorder rate was reduced from $22.06 \%$ to $13.01 \%$. The supply chain cost could be reduced and it clearly showed that storage control provides optimal utilization of available resources as an efficient space utilization can be reduced product shortage and warehouse operational costs to business goal achievement (Chen \& Yeh, 2013). Warehouse networking technology application can improve cargo management, operational management and accuracy inventory access. Excellence application network technology can reduce the warehouse workload and unnecessary losses by improving warehouse utilization and accuracy inventory warehouse management (Peng, 2014). In many industry sectors are adapt their own racks for inventory holding between production and delivery. It is very interested that rack designs have different types which is Last-In-First-Out propose particularly for product shelflife is most importance such as food industry. Rack design needs to consider either product size or product weight which can be keeping in difference tiers (Gebennini et al., 2011). Part of excellent plant and warehouse planning, the order picking equipments are most important. The picking equipments must be accurately matched to the order since it directly effect on cost effective management and goods precise. They have many kinds of picking system which help us to achieve high inventory securities and picking accuracies (Wilson, 1996).

Fuel cost has significantly effect on inventory levels and costs as the firms need to deliver inventories from their warehouses in one location to other location. If the distribution center is far away then fuel cost must be sharply increased. If gasoline price increase 1 percent, it will directly reduce 0.40 percent of inventory levels since the company is attempting to manage the cost (Jian-yu et al., 2014). Product delivery on time, productivity capacity and effective improvement and cost reduction are the main challenge for the companies to cope with a regular work basis. The production lines compatible should solve those problems and enhance regular work basis, the work station balancing help to improve production rate which is not interrupted (Gundogar et al., 2014). In the airline industries, the major cost is aircraft maintenance which shapely increasing to $13 \%$ of the total operation cost. The maintenance cast can be reduced by the good planning and IT system implementation. The method of GAMS provides the accuracy order when compare with commonly used such as reorder point system (ROP) and other forecasting method. The effective method helps company reduce cost and spare parts deliveries (Gu et al., 2015).

\section{Results}

Table 1 shows the mean and S.D results for these variables: space utilization, product sample holding method, product feature differentiation, effective inventory management system, inventory management objective, effective inventory picking system, inventory management cost reduction, regular problem happen, effective IT system and specific soft ware for inventory management. The results found that the firm responses were in the agreed level in which the mean=3.12 and S.D=0.83. Mean of Space utilization is 3.57. Mean of Product sample holding method is 3.54. Mean of Product feature differentiation is 3.51. 
Mean of Effective inventory management system is 3.42. Mean of Inventory management objective is 3.39. Mean of Effective inventory picking system is 3.32. Mean of Inventory management cost reduction is 2.95. Mean of Regular problem happen is 2.53. Mean of Effective IT system is 2.51 and Mean of specific soft ware for inventory management is 2.50 .

Table 1: The inventory management problems from large firms

\begin{tabular}{lll}
\hline Variables & mean & S.D \\
\hline Specific soft ware for inventory management & 3.58 & 0.93 \\
Effective IT system & 3.54 & 0.74 \\
Inventory management objective & 3.52 & 0.86 \\
Effective inventory picking system & 3.50 & 0.90 \\
Regular problem happen & 3.47 & 0.91 \\
Product feature differentiation & 3.42 & 0.75 \\
Inventory management cost reduction & 3.41 & 0.84 \\
Product sample holding method & 3.37 & 0.93 \\
Space utilization & 2.79 & 0.92 \\
Effective inventory management & 2.65 & 0.75 \\
Average & 3.32 & 0.85 \\
\hline
\end{tabular}

Table 2: The inventory management problems from small firms

\begin{tabular}{lll}
\hline Variables & mean & S.D \\
\hline Product feature differentiation & 3.46 & 0.74 \\
Inventory management objective & 3.45 & 0.92 \\
Product sample holding method & 3.45 & 0.87 \\
Effective inventory picking system & 3.41 & 0.87 \\
Space utilization & 3.18 & 0.92 \\
Inventory management cost reduction & 3.18 & 0.88 \\
Specific soft ware for inventory management & 3.04 & 0.83 \\
Effective inventory management & 3.03 & 0.75 \\
Effective IT system & 3.02 & 0.76 \\
Regular problems happen & 3.00 & 0.88 \\
Average & 3.22 & 0.84 \\
\hline
\end{tabular}

Table 2 shows the mean and S.D results for these variables: specific soft ware for inventory management, effective IT system, inventory management objective, effective inventory picking system, regular problem happen, product feature differentiation, inventory management cost reduction, product sample holding method, space utilization and effective inventory management. The results found that the firm responses were in the agreed level in which the mean=3.32 and S.D=0.85. Mean of Specific soft ware for inventory management is 3.58. Mean of Effective IT systemis 3.54. Mean of Inventory management objective is 3.52. Mean of Effective inventory picking system is 3.50. Mean of Regular problem happen is 3.47. Mean of Product feature differentiation is 3.42. Mean of Inventory management cost reduction is 3.41. Mean ofProduct sample holding method is 3.37. Mean of Space utilization is 2.79 and Mean of Effective inventory management is 2.65 .

Table 3 shows the mean and S.D results for these variables: product feature differentiation, inventory management objective, product sample holding method, effective inventory keeping, space utilization, inventory management cost reduction, specific soft ware for inventory management, effective inventory management, effective IT system and regular problems happen. The results found that the firm responses were in the agreed level in which the mean=3.22 and S.D=0.84. Mean of Product feature differentiation is 3.46. Mean of Inventory management objective is 3.45. Mean of Product sample holding method is 3.45 . Mean of Effective inventory picking system is 3.41. Mean of Space utilization is 3.18. Mean of Inventory management cost reduction is 3.18. Mean of Specific soft ware for inventory management is 3.04. Mean of Effective inventory management is 3.03. Mean of Effective IT system is 3.02 and Mean of Regular problems happen is 3.00. Appropriated warehouse designing and operation show the operational costs reduction since it can reduce overall travelling distance of operational chicken meat picking and transportation and it increases warehouse space utilization performance and inventory service level. 
When the excellence warehouse layout and picking system were implemented, the attractive return on investment has been realized (Tippayawong et al., 2013).

Table 3: The average of inventory management problems

\begin{tabular}{lll}
\hline Variables & mean & S.D \\
\hline Space utilization & 3.57 & 0.92 \\
Product sample holding method & 3.54 & 0.81 \\
Product feature differentiation & 3.51 & 0.73 \\
Effective inventory management system & 3.42 & 0.76 \\
Inventory management objective & 3.39 & 0.98 \\
Effective inventory picking system & 3.32 & 0.84 \\
Inventory management cost reduction & 2.95 & 0.92 \\
Regular problem happen & 2.53 & 0.85 \\
Effective IT system & 2.51 & 0.79 \\
Specific soft ware for inventory management & 2.50 & 0.73 \\
Average & 3.12 & 0.83 \\
\hline
\end{tabular}

Since the warehouse storage efficiency becomes crucial for inventory management and rack design is also paying a key role for inventory management. Small unit loads have been put in high lanes and easily for traveling in warehouse space which devoted to single rack method. As the volumetric utilization and storage efficiency are key performance indicators of warehouse management performance then optimal mix of racks heights needs to study (Ferrar et al., 2014). The accuracy recording in purchasing department under any uncertainty business environments and distribution uncertainty situations, all of the documents must be carefully checked before it was delivered. The accuracy picking systems particularly on stocks for customer orders must be prioritized. The accuracy order picking system highly concern in food distribution system as it directly effect on food quality and cost manners (Lancaster, 2000).

\section{Conclusion}

Effective inventory management for Thai entrepreneurs has different dimensions which depend on the size of the firms. The small size companies need space utilization rather than specific soft ware since they have limitation of their space, however large size companies need specific soft ware as they have many product items which holding in their warehouse. Specific soft ware will help them effectively manage their inventories. Inventory management cost is the most concerning of Thai entrepreneurs since it needs more knowledge and skills for effective inventory management. Many system such as just-in-time or lean system must be implemented to soar up Thai entrepreneurs' competitive advantage. Inventory management system needs or links with other supply chain management such as effective purchasing planning, raw materials deliveries, warehouse design, transportation system and distribution center locations then the integration of all knowledge significantly increase or improve inventory management capacities.

\section{References}

Chen, C. H. \& Yeh, C. C. (2013). Study on Inventory Policies for The On-line Shopping Company with Quick Response Service. Applied Mechanics and Materials, 2, 411-414.

Ferrara, A., Gebennini, E., Grassi, A. \& Rimini, B. (2014). An Optimization Model for the Design of Rack Stroage Systems. IIE Annual Conference and Expo, 2, 2540-2549.

Gebennini, E., Grassi, A., Rimini, B. \& Gamberini, R. (2011). A Multi-Item Multi-Rack Approach for Designing LofoStroage Systems: A Case Study From The Food Industry. 10 th International Conference on Modeling and Applied Simulation, MAS 2011, Held at the International Mediterranean and Latin American Modeling Multiconference, 13M 2011, Roam;Italy, 437-441.

Gu, J., Zhang, G. \& Li, K. W. (2015). Effective Aircraft Spare Parts Inventory Management under Demand Uncertainty. Journal of Air Transport Management, 42(1), 101-109.

Gundogar, E., Yilmaz, A. \& Erkayman, B. (2014). A Solution Approach to a Synchronisation Problem in a JIT Production System. Production Planning and Control, 25(12), 990-998.

Jian-yu, K., Dresner, M. \& Yuliang, Y. (2014). An Empirical Analysis of the Impact of Fuel Costs on the Level and Distribution of Manufacturing Inventory in the United States. Transportation Journal (PennsylvaniaStage University Press, 53(1), 5-25. 
Lancaster, M. (2000). Inventory Control. Businessdate, 8(3), 8-9.

Tippayawong, K.Y., Sopadang, A. \& Patitad, P. (2013). Improving Warehouse Layout Design of A Chicken Slaughterhouse Using Combined ABC Class Based and Optimized Allocation Techniques. Lecture Notes in Engineering and Computer Science, 1, 479-483.

Peng, Z. P. (2014). Analysis and Design of Supply Chain Inventory Management System Under Internet of Things Environment. Advance Materials Research, 3, 989-994.

Wilson, H. W. (1996). Orderpicking productivity takes good planning. Modern Materials Handling, 56, 2022. 